\title{
Internet food marketing on popular children's websites and food product websites in Australia
}

\author{
Bridget Kelly ${ }^{1, *}$, Katarzyna Bochynska ${ }^{2}$, Kelly Kornman $^{2}$ and Kathy Chapman ${ }^{1}$ \\ ${ }^{1}$ The Cancer Council NSW, PO Box 572, Kings Cross, New South Wales 1340, Australia: ${ }^{2}$ Department of \\ Nutrition and Dietetics, The University of Sydney, Sydney, New South Wales, Australia
}

Submitted 20 May 2007: Accepted 7 November 2007: First published online 26 February 2008

\begin{abstract}
Objective: The aim of the present study was to describe the nature and extent of food marketing on popular children's websites and food product websites in Australia.

Methods: Food product websites ( $n$ 119) and popular children's websites ( $n$ 196) were selected based on website traffic data and previous research on frequently marketed food brands. Coding instruments were developed to capture food marketing techniques. All references to food on popular children's websites were also classified as either branded or non-branded and according to food categories.

Results: Websites contained a range of marketing features. On food product websites these marketing features included branded education $(79 \cdot 0 \%$ of websites), competitions $(33 \cdot 6 \%)$, promotional characters $(35 \cdot 3 \%)$, downloadable items $(35 \cdot 3 \%)$, branded games $(28.6 \%)$ and designated children's sections $(21 \cdot 8 \%)$. Food references on popular children's websites were strongly skewed towards unhealthy foods $(60 \cdot 8 \% v .39 \cdot 2 \%$ healthy food references; $P<0 \cdot 001)$, with three times more branded food references for unhealthy foods. Branded food references displayed similar marketing features to those identified on food product websites.

Conclusions: Internet food marketing uses a range of techniques to ensure that children are immersed in brand-related information and activities for extended periods, thereby increasing brand familiarity and exposure. The relatively unregulated marketing environment and increasing use of the Internet by children point to the potential increase in food marketing via this medium. Further research is required to investigate the impact of Internet food marketing on children's food preferences and consumption, and regulatory options to protect children.
\end{abstract}

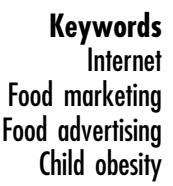

Childhood overweight and obesity in Australia is a major public health concern, with recent epidemiological data showing that almost $25 \%$ of school-aged children are overweight or obese ${ }^{(1)}$. Obesity is not only associated with a broad range of illnesses including psychosocial issues, orthopaedic problems and chronic diseases ${ }^{(2)}$, but is also estimated to contribute to immense economic burden. The overall cost of obesity in Australia in 2005 was estimated at AUS\$21 billion ${ }^{(3)}$. Childhood obesity is of particular concern, with research indicating that $44 \%$ of 5 -15-year-old children who are overweight, and $86 \%$ of obese children of the same age, will become overweight or obese adults ${ }^{(4)}$, with subsequent risk of early onset of obesity-related morbidity and premature mortality ${ }^{(5)}$.

While the interaction of many sociological, environmental and genetic influences is likely to contribute to childhood obesity, the issue of food marketing to children has been gaining momentum as a potential area for intervention. A report from the WHO concluded that the heavy advertising of energy-dense, micronutrient-poor food and beverages is a probable causal factor in childhood obesity, and has been cited as a target for future interventions ${ }^{(6)}$.

Previous research on food marketing to children has focused predominantly on television advertising ${ }^{(7)}$; however the use of non-broadcast media is becoming more common, with children now exposed to a high volume of messages from increasingly sophisticated and integrated marketing techniques ${ }^{(8)}$. The integration of commercial messages into all aspects of children's environments normalises promoted foods to children ${ }^{(9)}$. As the most frequently marketed food groups are pre-sugared 
breakfast cereals, savoury snacks, fast-food restaurant meals, confectionery and soft drinks ${ }^{(7)}$, the normalisation of these foods would be contrary to national nutrition guidelines.

Access to the Internet is increasing rapidly, with $65 \%$ of children aged 5 to 14 years now using the Internet ${ }^{(10)}$. Results from the NSW Schools Physical Activity and Nutrition Survey indicated that children are spending a large amount of their time in sedentary pursuits, mostly as small screen recreation, including the Internet, television and hand-held games ${ }^{(1)}$. The emergence of the Internet over the past decade has meant a shift in children's television viewing time to these other small screen activities ${ }^{(11)}$.

There have been two past studies from the USA that have analysed Internet food marketing to children on food product websites ${ }^{(12,13)}$. Research by Moore for the Henry J. Kaiser Family Foundation ${ }^{(12)}$ involved the analysis of ninety-six food company websites. Analysis compared results for high and low rating websites, based on website traffic data. Research by Weber et al. ${ }^{(13)}$ considered a smaller number of food company websites ( $n$ 40), however a large range of marketing characteristics were considered for each website. Both of these studies found that the Internet provided opportunities for creative and targeted marketing of unhealthy food to children, which could potentially engage children in brand-related activities for an extended period. These studies did not consider websites other than those specifically for food products. In Australia there has been no content analysis of Internet advertising to children.

The International Chamber of Commerce (ICC) recognises that children require special protection from Internet marketers ${ }^{(14)}$. The ICC Guidelines on Advertising and Marketing on the Internet outline only general guidelines relating to children, which centre around protecting children from commercial exploitation and encouraging supervision by parents and guardians ${ }^{(14)}$.

The aim of the present study was to systematically describe the nature and extent of food marketing on popular children's websites, based on website traffic data. As previous research on Internet food marketing from the USA has focused solely on food product websites ${ }^{(12,13)}$, equivalent Australian food product websites were also included for comparison. We sought to determine whether the food marketing features used in the USA were similar to those on Australian websites, and to determine if the level of unhealthy food marketing on the Internet was similar to levels already established to be on commercial television.

\section{Methods}

\section{Sampling of websites}

Internet traffic data for Australian children aged 2-16 years was purchased from Nielsen/Net Ratings ${ }^{(15)}$. All websites that attracted an audience of greater than $1.5 \%$ of the target population were included (30377 children and adolescents). This sample of popular children's websites consisted of a wide range of genres including search engines, news, newspapers, gaming, online shopping, sports, email, music, magazines, cartoons and television, movies and video. Additional food product websites were selected based on their frequency of marketing using other media, including television advertising and on-pack product promotions ${ }^{(16,17)}$.

Initially 324 websites were selected for inclusion (128 food product and 196 popular children's websites). Websites were excluded if they had been coded within another website or were unavailable $(n 9)$. The final website sample was 315 websites (119 food product and 196 popular children's websites).

\section{Coding}

Two coding instruments were produced to capture the characteristics of the websites. A pilot study was conducted on a small sample of websites $(n 4)$. Two research assistants analysed each website individually and discussed any discrepancies, with a brief revision of the coding system. All websites were then analysed by one of the two research assistants. Data coding took place throughout February 2007.

\section{Food product websites}

Characteristics used to assess food product websites were adapted from previous research on Internet marketing $^{(12,13)}$. These included the following.

1. Target audience

a. Young children (aged between 2 and 12 years): websites with fun, fantasy and adventure themes.

b. Adolescents (aged between 13 and 17 years): websites with fashion, image and sexuality themes.

c. General population: websites that targeted a range of age groups or with an unclear target audience.

2. Marketing features (Table 1).

Limits were placed on the number of website pages included from each website. For stand-alone (a specific website for a brand) and food manufacturer's websites, the entire site was included. For food brands which occupied a one-page link on a food manufacturer's website, only the product's page and two mouse clicks away from that page were included. These types of restrictions have been used in previous research for conciseness $^{(18,19)}$.

\section{Popular children's websites}

All food references were categorised into two major food categories, healthy foods and unhealthy foods, and further sub-categorised into twenty-three food groups 
Table 1 Internet marketing features present on food product websites

\begin{tabular}{|c|c|}
\hline Internet marketing feature & Total websites (\%) \\
\hline \multicolumn{2}{|l|}{ Brand identifiers } \\
\hline Brand logo & $99 \cdot 2$ \\
\hline Product packaging graphics & $91 \cdot 6$ \\
\hline Different brand variants & $82 \cdot 4$ \\
\hline Product as part of the background & $31 \cdot 9$ \\
\hline \multicolumn{2}{|l|}{ Gaming and children's sections } \\
\hline Advergaming $†$ & $28 \cdot 6$ \\
\hline Designated children's sections & $21 \cdot 8$ \\
\hline General gaming & $9 \cdot 2$ \\
\hline \multicolumn{2}{|l|}{ Promotions } \\
\hline Competitions & $33 \cdot 6$ \\
\hline Giveaways & $11 \cdot 8$ \\
\hline Fundraiser opportunities & $11 \cdot 8$ \\
\hline Product samples & $2 \cdot 5$ \\
\hline \multicolumn{2}{|l|}{ Promotional characters } \\
\hline Spokes characters & $17 \cdot 6$ \\
\hline Sports figures & $13 \cdot 4$ \\
\hline Celebrities & $2 \cdot 5$ \\
\hline Cartoon characters & $1 \cdot 7$ \\
\hline \multicolumn{2}{|l|}{ Partnerships and tie-ins } \\
\hline Links to other food websites & $73 \cdot 9$ \\
\hline Links to non-food websites & $49 \cdot 6$ \\
\hline Other brands used in premiums & $32 \cdot 8$ \\
\hline Television advertisement & $20 \cdot 2$ \\
\hline \multicolumn{2}{|l|}{ Downloads } \\
\hline Screen wallpaper & $15 \cdot 1$ \\
\hline Screensavers & $10 \cdot 1$ \\
\hline Desktop items & $9 \cdot 2$ \\
\hline Colouring pages & $5 \cdot \overline{9}$ \\
\hline \multicolumn{2}{|l|}{ Product benefit claims } \\
\hline Brand benefit claims & $89 \cdot 9$ \\
\hline Nutrition information & $66 \cdot 4$ \\
\hline Nutrition claims & $58 \cdot 8$ \\
\hline Healthy eating information & $21 \cdot 8$ \\
\hline Health claims & $14 \cdot 3$ \\
\hline \multicolumn{2}{|l|}{ Registration and accounts } \\
\hline Website memberships & $38 \cdot 7$ \\
\hline Benefits for members & $30 \cdot 8$ \\
\hline Viral marketing & $16 \cdot 0$ \\
\hline Website communities & $5 \cdot 9$ \\
\hline Online stores & $4 \cdot 2$ \\
\hline \multicolumn{2}{|l|}{ Educational material } \\
\hline Advercation‡ & $79 \cdot 0$ \\
\hline General education & $51 \cdot 3$ \\
\hline \multicolumn{2}{|l|}{ Child protection } \\
\hline Legal information & $87 \cdot 4$ \\
\hline Statement about 'cookies' & $68 \cdot 9$ \\
\hline Parental consent required & $19 \cdot 2$ \\
\hline Age blocks & 0.0 \\
\hline
\end{tabular}

tThe branded product is incorporated into the game.

$\ddagger$ The branded product is incorporated into the education material.

(Table 2). Food categories were based on those used in previous research on television food advertising to children $^{(17,20-22)}$ and according to the Australian Guide to Healthy Eating, the nationally recognised food guide for Australia $^{(23)}$. Websites were classified as manufacturer's sites if they contained information about a range of brands from varying food categories.

Every pictorial or written reference to food was included. All references were classified as either non-branded (a generic food reference) or branded (referring to a specific brand).
Table 2 The proportion of food category references on popular children's websites

\begin{tabular}{|c|c|}
\hline Food category & $\begin{array}{l}\text { Frequency } \\
\qquad \%)\end{array}$ \\
\hline \multicolumn{2}{|l|}{ Healthy food categories } \\
\hline $\begin{array}{l}\text { Core foods combined (including frozen meals, } \\
\text { soups ( } \mathrm{Na}<250 \mathrm{mg} / 100 \mathrm{~g} \text { ), sandwiches and } \\
\text { mixed salads) }\end{array}$ & $17 \cdot 0$ \\
\hline $\begin{array}{l}\text { Meat and meat alternatives (includes legumes, } \\
\text { nuts, peanut butter and eggs) }\end{array}$ & $6 \cdot 4$ \\
\hline Fruits and fruit products without added sugar & $6 \cdot 3$ \\
\hline $\begin{array}{l}\text { Vegetables and vegetable products without added } \\
\text { sugar }\end{array}$ & $5 \cdot 8$ \\
\hline $\begin{array}{l}\text { Breads, low-sugar/high-fibre breakfast cereals } \\
(<20 \% \text { sugar and dietary fibre }>5 \mathrm{~g} / 100 \mathrm{~g}) \text {, rice, } \\
\text { pasta and noodles (including high-fibre, low-fat } \\
\text { crackers) }\end{array}$ & $1 \cdot 8$ \\
\hline $\begin{array}{l}\text { Low-fat/reduced-fat milk, yoghurt, custard, cheese } \\
\text { and alternatives }\end{array}$ & $1 \cdot 0$ \\
\hline Water & 0.9 \\
\hline Baby foods & $0 \cdot 0$ \\
\hline Subtotal & $39 \cdot 2^{*}$ \\
\hline \multicolumn{2}{|l|}{ Unhealthy food categories } \\
\hline Alcohol & $11 \cdot 7$ \\
\hline $\begin{array}{l}\text { Recipes for other combined foods predominantly } \\
\text { high in fat, sugar and/or salt }\end{array}$ & $10 \cdot 8$ \\
\hline Chocolate and confectionery & $8 \cdot 3$ \\
\hline $\begin{array}{l}\text { Cakes, muffins, sweet biscuits, high-fat savoury } \\
\text { biscuits, pies and pastries }\end{array}$ & $8 \cdot 0$ \\
\hline $\begin{array}{l}\text { Snack foods, including crisps, extruded snacks, } \\
\text { popcorn, snack bars, muesli bars, sugar- } \\
\text { sweetened fruit and vegetable products and } \\
\text { sugar-coated nuts }\end{array}$ & $5 \cdot 5$ \\
\hline Fast-food restaurant meals & $4 \cdot 5$ \\
\hline $\begin{array}{l}\text { High-sugar drinks including soft drinks, cordials, } \\
\text { electrolyte drinks and flavour additions }\end{array}$ & $2 \cdot 9$ \\
\hline $\begin{array}{l}\text { Fats, spreads, sauces, meal helpers (stir fry sauces, } \\
\text { flavour bases) and soups }(\mathrm{Na}>250 \mathrm{mg} / 100 \mathrm{~g})\end{array}$ & $2 \cdot 6$ \\
\hline $\begin{array}{l}\text { Other non-core items, e.g. sugar-free chewing gum, } \\
\text { tea, coffee and yeast extracts }\end{array}$ & $2 \cdot 0$ \\
\hline $\begin{array}{l}\text { Full-cream milk, yoghurt, custard, dairy desserts, } \\
\text { cheese and alternatives }\end{array}$ & $2 \cdot 0$ \\
\hline Ice cream and iced confection & $1 \cdot 7$ \\
\hline $\begin{array}{l}\text { High-sugar/low-fibre breakfast cereals } \\
(>20 \% \text { sugar or dietary fibre }<5 \mathrm{~g} / 100 \mathrm{~g})\end{array}$ & 0.5 \\
\hline Fruit juice and fruit drinks & $0 \cdot 2$ \\
\hline Frozen/fried potato products & $0 \cdot 0$ \\
\hline Baby and toddler formulae & $0 \cdot 0$ \\
\hline Subtotal & $60 \cdot 8^{*}$ \\
\hline
\end{tabular}

${ }^{\star} P<0.001$.

Further classification of branded food references included the following.

1. Type of advertisement: direct advertisements (those placed on paid advertising space) or indirect marketing (included in editorial content or as a corporate sponsor).

2. Marketing features: brand identifiers, gaming, promotions, partnerships and tie-ins, promotional characters, child protection, graphics, movement, interactive components, sound, animation and music.

3. The size of the advertisement.

Only those pages that were within two mouse clicks from the website's home page were included. 


\section{Statistical analysis}

Data were entered into the Statistical Package for the Social Sciences statistical software package version 14.0 for Windows (SPSS Inc., Chicago, IL, USA). A Pearson $\chi^{2}$ test was applied to determine significant differences between the proportions of food references and the marketing methods used. Results were considered significant at the 0.05 level.

\section{Results}

\section{Food product websites}

Of the 119 food product websites, forty-eight were standalone sites, sixty-three were one-page links on a food manufacturer's website and eight were websites for food manufacturers. The majority of websites were classified as targeted towards the general population $(72 \cdot 2 \%)$, followed by those targeting young children (16.0\%) and adolescents $(11 \cdot 8 \%)$.

\section{Marketing features}

Table 1 shows a summary of the marketing features that were identified on food product websites. There were many instances of branding within the websites, with the majority of websites clearly displaying brand logos (99.2\%), product packaging graphics $(91 \cdot 6 \%)$ and available product variations $(82 \cdot 4 \%)$.

Overall, $28 \cdot 6 \%$ of websites contained 'advergames', where the branded food product is integrated into the interface of a computer game. The number of advergames varied between zero and sixty-seven per website. Websites targeting young children and adolescents had a significantly higher proportion of advergames than those targeting the general population $(57 \cdot 9 \%$ and $57 \cdot 1 \% v$. $\left.17 \cdot 4 \% ; \chi^{2}=18 \cdot 83, \mathrm{df}=2, P<0 \cdot 001\right)$. Websites for highsugar drinks and ice cream had the highest frequency of advergames (50.0\% of websites for these products), followed by websites for chocolate/confectionery (45.0\%). The majority of advergames incorporated brand logos $(75 \cdot 9 \%)$, features to extend game play $(59 \cdot 0 \%)$ such as prompting children to play again, and sound (53.0\%). In many games, the food product or branded 'spokes character' (the mascot for the brand) was the central focus ( $43 \cdot 4 \%$ and $36 \cdot 1 \%$, respectively).

Of websites containing designated children's sections, $15 \cdot 4 \%$ had website memberships available. No sites required product purchase to enter. These designated children's sections were not only found on websites targeting children; $23.3 \%$ of websites targeted towards the general population contained children's sections.

Spokes characters and sports celebrities were the most frequently used promotional characters. Of the websites targeting young children, $57 \cdot 9 \%$ contained spokes characters. This compared with only $21 \cdot 4 \%$ and $8 \cdot 1 \%$ of those targeting adolescents and the general population, respectively. Websites targeting adolescents had the highest frequency of sports celebrities (28.6\%).

Linking the website to other sites was frequently used to extend children's website experience, typically as a link to another of the manufacturer's brands $(73.9 \%$ of all websites). Television advertisements were incorporated on $20 \cdot 2 \%$ of websites, $83 \cdot 3 \%$ of which provided an advertisement break warning.

Overall, $35 \cdot 3 \%$ of websites contained at least one downloadable item such as screen wallpaper, screensavers, desktop items and colouring pages. Of the websites containing downloadable items, many contained multiple downloadable items, with a total of forty-six individual downloadable items across all food product websites. These items were more concentrated on websites targeting young children $(52.6 \%$ v. $32.5 \%$ and $28.6 \%$ for the general population and adolescents, respectively; $\chi^{2}=3 \cdot 06, \mathrm{df}=2$, NS).

Claims about the proposed benefits of the branded product, relating to its sensory characteristics including taste, texture, appearance and aroma, were evident on $83 \cdot 2 \%$ of all websites. Emotive claims, often relating to fun and popularity associated with the product, were present on more than half of websites $(52 \cdot 1 \%)$.

Basic nutrition information, including nutrient content and information about allergens, appeared on $66.4 \%$ of websites. Specific nutrition claims relating to micronutrients, additives, caffeine and other nutrients were also common, featuring on $58.8 \%$ of websites. Information about healthy eating strategies and health claims, which linked the product to disease prevention or improved physiological function, was present to a lesser extent $(14 \cdot 3 \%)$.

Websites contained features to allow individuals to customise the site and have greater control and interaction with the interface. These included features to create a personal account, participate in a website community (where the site emulates a community in which the child can interact) or be involved in online shopping. Website memberships were available on $38.7 \%$ of websites, while only a small number of websites contained website communities and online stores $(5 \cdot 9 \%$ and $4 \cdot 2 \%$, respectively).

The majority of websites contained 'advercation' (79.0\%), where the food product is integrated into education material, most commonly as historical facts relating to the product or company $(87 \cdot 2 \%$ of all forms of advercation). The proportion of websites containing advercation was higher than those containing other general education material not relating specifically to the brand $(51 \cdot 3 \%)$.

Features designed to protect children from inappropriate material or to protect their privacy included legal information $(87 \cdot 4 \%$ of websites), statements about 'cookies' (68.9\%) and the requirement of parental consent to enter the website or designated children's 
section $(19 \cdot 2 \%)$. None of the websites contained age blocks.

\section{Popular children's websites}

Of all popular children's websites, 43.9\% ( $n$ 86) contained food references. Websites that did not contain food references were excluded from the following analysis. Of those popular children's websites that did contain food references, those targeting the general population were the most common $(86.7 \% v \cdot 10 \cdot 6 \%$ and $2.7 \%$ targeting young children and adolescents, respectively). Websites encompassed a wide range of genres, with almost a third being for television channels, movies and videos.

\section{Food references}

Overall, 932 food references were found on the eighty-six websites, almost eleven references per site. There were significantly more food references for unhealthy food compared with healthy food categories (60.8\% v. 39.2\%; $\left.\chi^{2}=43 \cdot 78, \mathrm{df}=1, P<0 \cdot 001\right)$.

The most frequently referenced food categories were core foods combined (17.0\% of food references), followed by alcohol $(11 \cdot 7 \%)$, recipes $(10 \cdot 8 \%)$, chocolate/ confectionery $(8 \cdot 3 \%)$ and cakes, muffins, sweet biscuits, high-fat savoury biscuits, pies and pastries $(8.0 \%)$ (Table 2).

There was a higher proportion of unhealthy food advertising on websites targeting adolescents than on those targeting the general population and young children $(76 \cdot 0 \% v \cdot 60 \cdot 6 \%$ and $58 \cdot 6 \%$ of total food references on these sites; $\chi^{2}=2 \cdot 64$, $\mathrm{df}=2$, NS).
There was a higher frequency of non-branded food references for both healthy and unhealthy food categories. However, there were almost three times more branded food references for unhealthy foods compared with healthy foods $(23.6 \% v .8 \cdot 2 \%)$. The specific food categories with the highest proportion of branded food references were high-sugar/low-fibre breakfast cereals (100.0\% of all references for this food group were branded), high-sugar drinks (70.4\%) and fast-food restaurant meals $(57 \cdot 1 \%)$ (Fig. 1).

\section{Branded food references}

Overall, $17 \cdot 6 \%$ of all food references were branded, with 164 branded references found on popular children's websites. The majority of branded food references were direct advertisements $(70 \cdot 1 \%)$.

Frequently used marketing features included the use of graphics $(78.0 \%$ of websites), brand $\operatorname{logos}(75 \cdot 0 \%)$, corporate $\log$ os $(52 \cdot 4 \%)$, links to a food product website $(42 \cdot 1 \%)$ and the inclusion of a product package $(35 \cdot 4 \%)$. Sound, animation and music were less frequently used ( $4 \cdot 9 \%, 4 \cdot 3 \%$ and $1 \cdot 2 \%$, respectively). Only $2 \cdot 4 \%$ of websites containing branded food references included a television advertisement, $75 \cdot 0 \%$ of which displayed an advertisement warning.

Of those websites containing a branded food reference $9 \cdot 1 \%$ offered premiums, including competitions and giveaways. The use of premiums was similar for healthy and unhealthy food references $(10 \cdot 0 \% v$. 9.0\%, respectively). The most frequently used premiums were competitions that did not require a barcode to enter (no pre-purchase

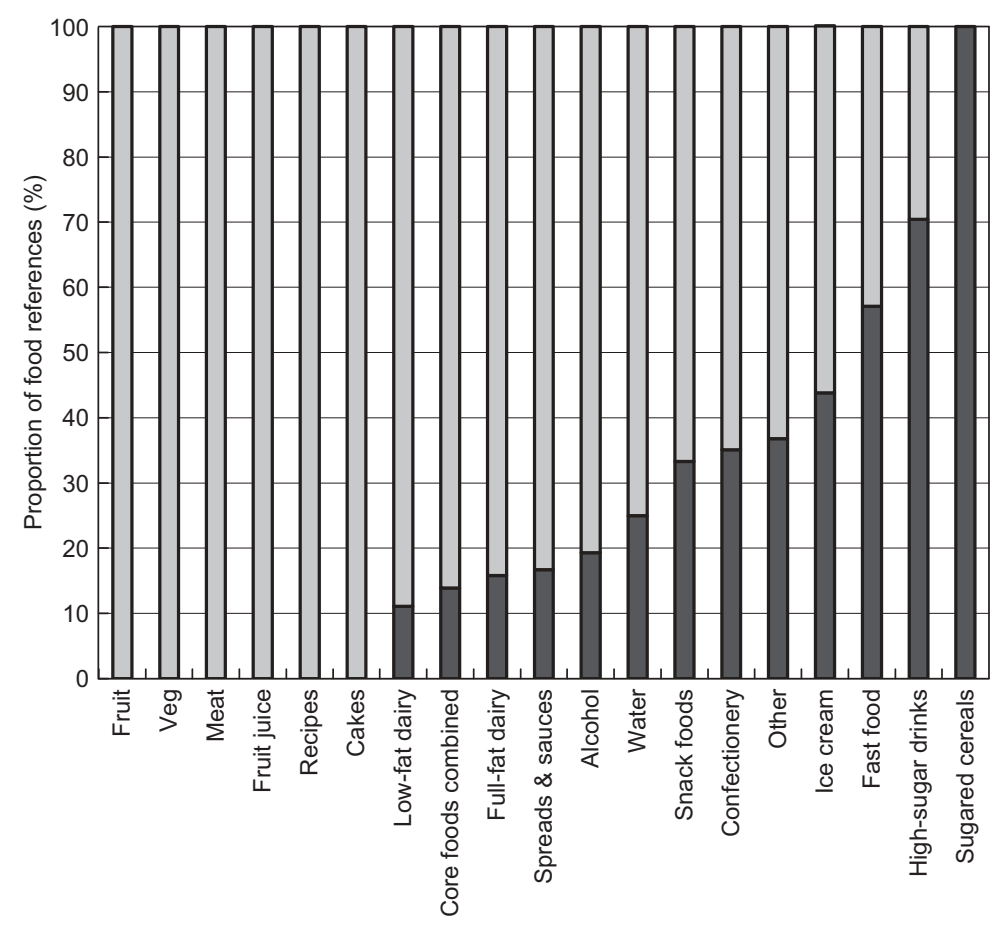

Fig. 1 The frequency of branded $(\square)$ and non-branded $(\square)$ food references by food category on popular children's websites 
of product needed) ( $40 \cdot 0 \%$ of all premiums), followed by those requiring a barcode for entry (33.3\%). However, these proportions represent only a small number of websites.

The majority of direct advertisements were relatively small in size, with those taking up less than a quarter of the screen contributing to $85.9 \%$. Pop-up advertisements accounted for $10.9 \%$ of direct advertisements.

No child protection features were found on websites with branded food references, with no legal information, statements about cookies, information to parents, parental consent required to enter the sites or age blocks found on any of the websites.

Analyses comparing more popular websites (reaching greater than $15 \%$ of the target population) with less popular websites (reaching less than $15 \%$ ) indicated no significant differences in the types of food products that were marketed (results not shown here).

\section{Discussion}

Various Internet food marketing techniques were identified, many of which appeared to be designed specifically to target children. These techniques act to reinforce the food brand and increase children's exposure time to the product. The 'sticky' nature of the Internet, in that it captures and maintains children's attention for extended periods, makes it a potent marketing medium ${ }^{(19)}$. The large sample of Internet sites that was included in the current study adds strength to the research findings, and helps to more clearly assess the extent of food marketing across the expansive Internet environment.

To our knowledge, the present study provides the first published research that has assessed the extent of food marketing on a range of popular children's websites; previous research has focused solely on food product websites. Website traffic data indicated that Australian children visit other, non-food websites more frequently than food product websites, with the most popular nonfood websites reaching up to $85.3 \%$ of children aged 2-16 years or 1.7 million children ${ }^{(15)}$. The analysis of popular children's websites provides a more accurate representation of children's exposure to Internet food marketing. Many of the websites that contained the highest proportions of food references were those typically considered to be a source of information and education, rather than advertising, such as websites for news and newspapers.

On popular children's websites, food references were strongly skewed towards unhealthy foods. This disproportionate frequency of unhealthy food referencing has been demonstrated in previous research on television food advertising ${ }^{(17,20,21)}$. Recent Australian research, which assessed the extent of television food advertising to children, has shown that between $48 \cdot 6 \%{ }^{(17)}$ and
$81 \cdot 5 \%{ }^{(20)}$ of all food advertisements are for high-fat/highsugar or non-core foods.

Both the high frequency and the nature of unhealthy food references on the Internet are of concern. For example, some alcohol references promoted excess consumption, with its inclusion in games where participants were instructed to outdrink their opponents, achieved by continually pressing the 'drink' button featured on the screen. There are currently no regulations that limit the marketing of alcohol to children on the Internet. This is in contrast to the Children's Television Standards, which state that advertisements for alcohol may not be broadcast during children's television programmes ${ }^{(24)}$.

The majority of branded food references were direct advertisements which used similar defining features to those identified in previous Internet food marketing research $^{(12,13)}$ and indeed on food product websites in the current study, including the use of brand logos, product graphics, links to food product websites and premium offers. Although these direct advertisements tended to be relatively small in size, they were often repeated on each distinct page, reinforcing the branded product throughout the website.

Considering food product websites, many of these sites appeared to be targeted specifically towards young children and adolescents, with many containing themes that would be appealing to either group, or containing designated children's sections. Advergaming was available on the majority of websites targeting young children and adolescents. The number of games on each website varied, with an overwhelming number of games available on some sites and more games available on websites for high-sugar drinks, ice cream and chocolate/confectionery.

There were many other techniques that were used to attract children to the brand on food product websites, including through the use of promotional characters and sports figures. The Children's Advertising Review Unit in the USA, the self-regulatory agency for the advertising industry, has recognised that the association of a character with a product significantly alters children's perceptions of that product ${ }^{(25)}$. There is a potential that young children will form strong attachments with familiar cartoon characters. As some of these spokes characters are effectively integrated into children's lives, in the form of commercial activities from a range of media, the formation of a relationship with these promotional characters, and thus the branded food product, is easy to envisage. Similarly, professional sports people can help to create positive brand images. Often there is a discord between the type of food product being promoted and the association of this product with people who are perceived to be healthy.

Facilities on the Internet allow for the integration of other marketing media, such as television advertisements. 
In some cases these television advertisements were integrated with other children's activities, making it difficult for young children to differentiate between the advertisement and other non-commercial activities.

There are no statutory regulations currently applied to Australian websites. However, online marketing is subject to the voluntary Food and Beverages Advertising and Marketing Code developed by the Australian Association of National Advertisers ${ }^{(26)}$. This code of practice only covers paid advertisements; it does not preclude marketing techniques used on a food company's own website. Internationally, previous attempts to regulate Internet content have failed, primarily due to its constantly changing structure, whereby regulations are quickly made redundant, and its global nature, so that those wishing to avoid regulations can simply move their site off-shore ${ }^{(19)}$.

While many of the same child-oriented Internet marketing features were found on Australian food product websites as were reported in previous literature from the USA ${ }^{(12,13)}$, most were not as prevalent on Australian websites; for example, there was a two ${ }^{(13)}$ to two-and-ahalf $^{(12)}$ times higher proportion of advergames and a three times higher proportion of spokes characters ${ }^{(13)}$ on US websites. However, it is foreseeable that with the possible advent of tighter television advertising regulation for children following recent debate in Australia ${ }^{(27)}$, and the less regulated environment for Internet food marketing, use of this medium may expand further. Additionally, the Internet's interactive nature that allows children to engage with a food product ${ }^{(12)}$ and its relatively low cost may make the Internet more attractive for food marketers compared with television advertising ${ }^{(28)}$.

Options for Internet regulations relating to food product websites could include the mandatory inclusion of nutrition information for all food products, similar to that outlined by Food Standards Australia and New Zealand relating to nutrition information panels on all commercially packaged foods ${ }^{(29)}$. This information should be readily available for all food products. In the current study only two-thirds of food product websites contained nutrition information, allowing food products with less desirable nutrient profiles to omit these details. Restrictions for Internet food marketing targeting children could be linked to only those foods with less desirable nutrient criteria, as defined by a nutrient-profiling model similar to that developed by the Food Standards Agency in the UK for regulation on television food advertising to children ${ }^{(30)}$.

Other regulatory options could include children's privacy protection and age blocks. Such privacy laws may protect children from disclosing personal information, which marketers can use to further target children. In the current study $30 \cdot 8 \%$ of websites offered incentives to website members, encouraging children to provide their personal details. Some websites contained statements about age requirements and parental permission; however this was not regulated.

There are few data available relating to the effect of Internet marketing on children's perceptions or behaviour. One published study that assessed adolescents' exposure to websites and tobacco smoking ${ }^{(20)}$ showed that exposure to websites containing tobacco advertising was similar in smokers and non-smokers; however this is likely to have been confounded by other sources of tobacco marketing. Further research is necessary to determine the impact that this type of marketing has on children's food preferences and consumption.

The current study provides data about the nature and extent of food advertisements on the Internet and, by analysing websites that are most popular with children, allows for a more accurate depiction of children's actual exposure to this marketing. The wide reach of these popular websites, some reaching up to $85 \cdot 3 \%$ of children, highlights children's potential exposure to food marketing and the extent of their interaction with this type of small screen activity.

\section{Acknowledgements}

This project was funded by The Cancer Council NSW. The authors confirm that there were no conflicts of interest.

All authors of this paper were responsible for the study design and contributed substantially to the paper development. K.C. was responsible for the acquisition of funding and in providing guidance on the project. B.K. was responsible for implementing the project and data analysis. K.K. and K.B. were responsible for the collection of Internet advertising data.

The authors wish to thank the NSW Department of Health who provided infrastructure funding to support this project.

\section{References}

1. Booth M, Okely AD, Denney-Wilson E, Hardy L, Yang B \& Dobbins T (2006) NSW School Physical Activity and Nutrition Survey (SPANS) 2004: Full Report. Sydney: NSW Department of Health.

2. Fontaine KR, Redden DT, Wang C, Westfall AO \& Allison DB (2003) Years of life lost due to obesity. JAMA 289, 187-193.

3. Access Economics (2006) The economic costs of obesity. http://www.accesseconomics.com.au/publicationsreports/ showreportphp?id=102 (accessed April 2007).

4. Venn AJ, Thomson RJ, Schmidt MD, Cleland VJ, Curry BA, Gennat HC \& Dwyer T (2007) Overweight and obesity from childhood to adulthood: a follow-up of participants in the 1985 Australian Schools Health and Fitness Survey. Med J Aust 186, 458-460.

5. Australasian Society for the Study of Obesity (2004) Obesity in Australian children. http://www.asso.org.au/freestyler/ gui/files//factsheet_children_cons_causes_prev_mment.pdf (assessed April 2007). 
6. World Health Organization (2003) Diet, Nutrition and the Prevention of Chronic Diseases. Joint WHO/FAO Expert Consultation. WHO Technical Report Series no. 916. Geneva: WHO.

7. Hastings G, Stead M, McDermott L, Forsyth A, MacKintosh AM, Rayner M, Godfrey C, Caraher M \& Angus K (2003) Review of the Research on the Effects of Food Promotion to Children. Glasgow: Centre for Social Marketing.

8. Dalmeny K, Hanna E \& Lobstein T (2003) Broadcasting Bad Health: Why Food Advertising Needs to be Controlled. London/Washington/Ottawa/Tokyo: International Association of Consumer Food Organizations for the WHO consultation on a global strategy for diet and health.

9. Hoek J \& Gendall P (2006) Advertising and obesity: a behavioural perspective. J Health Commun 11, 409-423.

10. Australian Bureau of Statistics (2006) Survey of Children's Participation in Cultural and Leisure Activities. http://www. abs.gov.au/ausstats/abs@.nsf/mf/4901.0?OpenDocument (accessed February 2007).

11. Federal Trade Commission and Department of Health \& Human Services (2006) Perspectives on marketing, selfregulation \& childhood obesity. http://www.ftc.gov/os/ 2006/05/PerspectivesOnMarketingSelf-Regulation\&ChildhoodObesityFTCandHHSReportonJointWorkshop.pdf (accessed February 2007).

12. Moore E (2006) It's Child's Play: Advergaming and the Online Marketing to Children. Washington, DC: Kaiser Family Foundation.

13. Weber K, Story M \& Harnack L (2006) Internet food marketing strategies aimed at children and adolescents: a content analysis of food and beverage brand web sites. J Am Diet Assoc 106, 1463-1466.

14. International Chamber of Commerce (1998) Guidelines on Advertising and Marketing on the Internet. http://www. iccwbo.org/home/statements_rules/rules/1998/internet_ guidelinesasp (accessed February 2007).

15. Net Ratings Australia Pty Ltd (2007) Home page on the Internet. http://www.nielsen-netratings.com/ (assessed February 2007).

16. Chapman K, Nicholas P, Banovic D \& Supramaniam R (2006) The extent and nature of food promotion directed to children in Australian supermarkets. Health Promot Int 21, 331-339.

17. Kelly B, Smith B, King L, Flood V \& Bauman A (2007) Television food advertising to children: the extent and nature of exposure. Public Health Nutr 10, 1234-1240.
18. Dragicevich H, Williams PG \& Ridges L (2006) Survey of health claims for Australian foods made on Internet sites. Nutr Diet 63, 139-147.

19. Ribisl KM (2003) The potential of the internet as a medium to encourage and discourage youth tobacco use. Tob Control 12, Suppl. 1, i48-i59.

20. Chapman K, Nicholas P \& Supramaniam R (2006) How much food advertising is there on Australian television? Health Promot Int 21, 172-180.

21. Neville L, Thomas M \& Bauman A (2005) Food advertising on Australian television: the extent of children's exposure. Health Promot Int 20, 105-112.

22. Wilson N, Quigley R \& Mansoor O (1999) Food ads on TV: a health hazard for children? Aust N Z J Public Health 23, $647-650$

23. Australian Government Department of Health and Aging (1988) The Australian Guide to Healthy Eating. http:// www.health.gov.au/internet/wcms/Publishing.nsf/Content/ health-pubhlth-strateg-food-guide-index.htm (accessed March 2007).

24. Australian Communications and Media Authority (2005) Children's Television Standards. http://www.aba.gov.au/ contentreg/codes/television/documents/chstdvarn_03pdf (accessed February 2007).

25. Center for Science in the Public Interest (2003) Pestering parents: how food companies market obesity to children. http://www.cspinet.org/new/200311101.html (accessed November 2006).

26. Australian Association of National Advertisers (2006) Food and Beverages Advertising and Marketing Communications Code. http://www.aana.com.au/pdfs/FoodCode_Launch\% 20Version.pdf (accessed February 2007).

27. Coalition on Food Advertising to Children (2006) Children's Health or Corporate Wealth? A Case for Banning Television Food Advertising to Children. Australia: Coalition on Food Advertising to Children.

28. Hawkes C (2004) Marketing Food to Children: The Global Regulatory Environment. Geneva: WHO.

29. Food Standards Australia New Zealand (2006) General information on the code online http://www.foodstandards. gov.au/newsroom/factsheets/industryfactsheetsfsc/general informationon1215.cfm (accessed February 2007).

30. Food Standards Agency (2006) Guide to using the model. http://www.food.gov.uk/healthiereating/advertisingtochildren/ nutlab/nutprofmod (accessed September 2007). 